Review Article

\title{
A Review of the Engineering Properties of Metakaolin Based Concrete: Towards Combatting Chloride Attack in Coastal/ Marine Structures
}

\author{
Deveshan L. Pillay, ${ }^{1}$ Oladimeji B. Olalusi ${ }^{1},{ }^{1}$ Paul O. Awoyera $\left(\mathbb{D},{ }^{2}\right.$ Carlos Rondon, ${ }^{3}$ \\ Ana María Echeverría, ${ }^{3}$ and John Temitope Kolawole $\mathbb{C}^{4}$ \\ ${ }^{1}$ Department of Civil Engineering, Structural Engineering \& Computational Mechanics Group (SECM), \\ University of KwaZulu-Natal, Durban, South Africa \\ ${ }^{2}$ Department of Civil Engineering, Covenant University, Ota, Nigeria \\ ${ }^{3}$ Universidad de la Costa, Barranquilla, Colombia \\ ${ }^{4}$ Department of Civil Engineering, Stellenbosch University, South Africa
}

Correspondence should be addressed to Oladimeji B. Olalusi; olalusio@ukzn.ac.za

Received 27 August 2020; Revised 5 September 2020; Accepted 16 September 2020; Published 5 October 2020

Academic Editor: Mehmet Serkan KIRGIZ

Copyright $\odot 2020$ Deveshan L. Pillay et al. This is an open access article distributed under the Creative Commons Attribution License, which permits unrestricted use, distribution, and reproduction in any medium, provided the original work is properly cited.

\begin{abstract}
Changing human lifestyle and increasing urbanisation are contributory factors to the high demand for concrete construction materials across the globe. With the imminent developments in the unpopulated marine/coastal zones, higher installation of concrete facilities is still expected. However, poor design and construction procedures coupled with inadequate materials selection and exposure to aggressive environmental conditions, such as chloride laden environments, often result in the reduced aesthetic and structural performance of concrete. Deterioration of reinforced concrete structures located in a coastal/marine setting can influence the safety, economic, and sustainability aspects of society. Hence, there is an increased need for alternate binder systems with the ability to reduce the effects of chloride attack in concrete. This paper presents a critical review of the engineering properties of metakaolin (MK) based concrete exposed to chloride attack. The key advantages and limitations of using MK for concrete production purposes were outlined and evaluated. Areas for future research were also highlighted in this paper. Based on the favourable 28-day compressive strength (73-84 MPa) and durability performance documented across the numerous past year studies that were reviewed, it can be concluded that MK is a viable alternate binder material for combatting chloride attack in coastal/marine concrete structures. This, in conjunction with its lack of chemical $\mathrm{CO}_{2}$ emissions, proves that $\mathrm{MK}$ can be used to improve the serviceability and sustainability states of marine structures. The viewpoint of this review will guide concrete constructors and researchers on a possible framework for the utilisation of metakaolin for enhancing durability concrete in aggressive environments.
\end{abstract}

\section{Introduction}

Concrete made from Portland cement is renowned for its superior durability properties and versatility, which is why it is the most widely used material in the construction industry. However, poor design and construction practices, inadequate materials selection, and exposure to severe conditions, such as chloride laden environments, often result in the deterioration of the aesthetic and structural aspects of concrete [1].

More than $1 \mathrm{~m}^{3}$ of concrete is estimated to be produced per individual per year on a global scale [2]. Approximately 5 to $7 \%$ of the human-induced carbon dioxide $\left(\mathrm{CO}_{2}\right)$ emissions can be attributed to the cement manufacturing industry [2-4]. The global annual cement production in 2020 is anticipated to be around 5.9 billion tons, which amounts 
to 4.8 billion tons of $\mathrm{CO}_{2}$ that will be produced [5]. Sulphur trioxide $\left(\mathrm{SO}_{3}\right)$ and nitrogen oxides $\left(\mathrm{NO}_{\mathrm{X}}\right)$ are some of the other harmful greenhouse gases that are released during the cement manufacturing process and can also have an adverse environmental impact. Along with releasing toxic greenhouse gases into the atmosphere, the Portland cement (PC) production process is also responsible for the consumption of large quantities of raw materials and energy.

The ever-expanding population and physical attributes experienced on a local and global scale are the main factors associated with the increased demand for future development. It is anticipated that the majority of this development will take place in marine and coastal regions. This can be accredited to the satisfactory trade and transport prospects, suitable locations for human settlements, and ease of access linked with these areas [6].

The deterioration of reinforced concrete marine structures impacts the safety, economy, and sustainability aspects of everyday life [7]. A large economic burden is placed on society, which results from the excessive amount of concrete being produced to repair and rehabilitate deteriorated concrete as opposed to being used in new construction schemes. Therefore, coastal engineers must understand the long-term durability factors of marine concrete structures.

Chloride attack is the main factor affecting the durability of reinforced concrete structures situated in marine and coastal regions $[8,9]$. The penetration of chloride ions into concrete also plays a vital role in the physical and chemical processes associated with deterioration of the microstructure of concrete and the corrosion of steel reinforcement [10]. This ultimately results in unsafe marine structures, with reduced service life.

The corrosion mechanism is initiated when a critical concentration of chloride ions has accumulated at the steel reinforcement [11]. The deterioration associated with chloride-induced corrosion of reinforced concrete structures is not only reported to be a major durability problem in South Africa but all across the world [7].

The propagation of chloride attack, which leads to cracking, spalling, and reduction of load-bearing capacity in reinforced structures, is initiated by expansion/contraction and hydration/dehydration cycles [7]. In marine and coastal environments, these cycles are dependent on variations in temperature and humidity.

The climate on the east coast of South Africa (i.e., Durban) is described as subtropical and humid, with significantly higher volumes of precipitation in comparison with other regions of South Africa [6]. In the absence of a strong upwelling of cold bottom water on the east coast, the water temperature along the Durban coast is found to be warmer and ranges from 18 to $27^{\circ} \mathrm{C}$ [6]. The propagation of chloride attack increases when concrete is exposed to warm climates and seawater that is saline [8].

Extensive research into the durability problems associated with chloride attack in concrete has incorporated the use of recycled materials and secondary products in concrete [12]. From a marine and coastal engineering perspective, there is an increased need for alternate binder systems with the ability to reduce the penetration of chloride ions.
Alternate binder systems are often used to improve the durability, along with the fresh and hardened state properties of concrete exposed to a chloride laden environment [13]. It has been well documented that the use of an alternative binder reduces the cement content thereby reducing the heat of hydration, while also improving the durability by reducing the permeability and thus improving concrete's resistance to chloride attack [13-15].

This contribution presents previous studies on the use of metakaolin (MK) as an alternative binder system to combat chloride attack in concrete. MK is still a fairly new cementitious material to the South African concrete industry, with fly ash being the more commonly used option for combatting chloride attack in Durban Harbour. MK is a supplementary cementitious material whose application in concrete structures dates back to the 1960s when Jupia Dam was constructed in Brazil [16]. MK differs from secondary cementitious binder materials, such as ground granulated blast furnace slag (GGBS), fly ash (FA), and condensed silica fume (CSF) in the sense that it is not a by-product from industrial processes.

MK is categorised as being a highly reactive pozzolan that displays favourable concrete performance characteristics when utilised in combination with FA and GGBS. This leads to an increased amount of cement being replaced, which reduces the overall greenhouse gas emissions and subsequently improves the sustainability and financial properties of concrete. As shown in Table 1, using MK as a supplementary cementitious material can have a significant impact on concrete performance. To critically assess the viability of $\mathrm{MK}$ for use in combatting chloride attack in concrete, it is crucial to gain a detailed understanding of its engineering properties. Therefore, this review paper aims to consolidate the findings documented across various research studies to gain further insight into the performance of concrete incorporating $\mathrm{MK}$ as a partial cement replacement, with a primary focus on its structural behaviour and the fresh state and mechanical and durability properties.

\section{Methodology}

An extensive search of published research papers about the use of MK as a partial cement replacement in concrete was performed by using major search engines, such as Science Direct and Google Scholar. The research articles were selected according to their significance to this review, while the number of individual citations was not applied as a selection criterion. The research papers were then categorised and organised in accordance with their relevance to the fresh state and mechanical and durability properties of concrete (Figure 1). The numerous engineering properties documented in the past year and studies were extracted and critically reviewed. The similarities and differences observed between the various studies were noted and discussed in detail. Therefore, the research conducted in this paper will serve as a valuable guide for future researchers and construction industry professionals. This review paper has been split into six sections. Section 3 outlines the material properties of $\mathrm{MK}$, including its manufacturing process, 
TABle 1: Previous studies on the engineering properties of concrete containing varying amounts of metakaolin (MK).

\begin{tabular}{|c|c|c|c|c|}
\hline $\begin{array}{l}\text { Research } \\
\text { study }\end{array}$ & $\begin{array}{l}\text { MK } \\
(\%)\end{array}$ & $\begin{array}{l}\text { Water-binder } \\
\text { ratio }\end{array}$ & $\begin{array}{l}\text { Properties } \\
\text { researched }\end{array}$ & Findings \\
\hline [16] & 2 to 6 & 0.45 & Mechanical & $\begin{array}{l}\text { Compressive strength of the MK samples cured in a chloride laden setting is } \\
\text { higher than the control; optimum MK content is } 5 \% \\
\text { Porosity and chloride resistance improved as the MK content and concrete age } \\
\text { increased }\end{array}$ \\
\hline [17] & 5 to 25 & 0.42 & Fresh & Workability decreased as the MK content increased \\
\hline [18] & 5 to 15 & - & Fresh & Workability decreased as the MK content increased \\
\hline [19] & $5 \& 15$ & $0.25 \& 0.35$ & $\begin{array}{l}\text { Mechanical } \\
\text { Durability }\end{array}$ & $\begin{array}{l}\text { Compressive strength of the MK samples is superior to the control samples } \\
\text { MK enhanced the permeability properties; sorptivity coefficient decreased as the } \\
\qquad w / b \text { ratio was reduced }\end{array}$ \\
\hline [20] & 5 to 15 & 0.35 & Mechanical & $\begin{array}{l}\text { Strength increased as the MK content increased; optimum compressive strength } \\
\text { results for } 15 \% \mathrm{MK}\end{array}$ \\
\hline [21] & 5 to 30 & 0.45 & Mechanical & $\begin{array}{c}\text { Compressive strength increased as the MK content increased; limited strength } \\
\text { development after } 28 \text { days }\end{array}$ \\
\hline [22] & 5 to 20 & $0.25 \& 0.5$ & Mechanical & $\begin{array}{l}\text { Optimum strength results between } 10 \text { and } 15 \% \text {; no limited strength development } \\
\text { after } 28 \text { days }\end{array}$ \\
\hline [23] & 8 & - & Mechanical & $\begin{array}{c}\text { Improved compressive and flexural strength observed in the concrete samples } \\
\text { containing MK }\end{array}$ \\
\hline [24] & 5 to 20 & 0.49 & Mechanical & $\begin{array}{l}\text { Concrete samples containing the coarser MK displayed reduced permeability } \\
\text { Compressive strength increased up until 15\% MK level; optimum MK content is } \\
\qquad 5 \%\end{array}$ \\
\hline
\end{tabular}

chemical composition, morphology, hydration process, carbon footprint, and economic properties. Section 4 includes a review of the fresh state properties of MK concrete. The mechanical properties, namely, compressive and flexural strength, are reviewed in Section 5, while Section 6 discusses the durability performance, and Section 7 presents the concluding remarks and areas for future research.

\section{Material Properties of Metakaolin}

3.1. Manufacturing Process and Chemical Composition. Metakaolin is produced by heating kaolin, which is a natural clay mineral, to a temperature between $650^{\circ} \mathrm{C}$ and $800^{\circ} \mathrm{C}$ [25]. Exceeding this temperature leads to the metakaolin becoming nonreactive and inert [26]. Equation (1) shows that when kaolin $\left(\left(\mathrm{Al}_{2} \mathrm{Si}_{2} \mathrm{O}_{5}(\mathrm{OH})_{4}\right)\right.$ or $\left.\mathrm{AS}_{2} \mathrm{H}_{4}\right)$ is heated, it is converted into metakaolin $\left(\left(\mathrm{Al}_{2} \mathrm{Si}_{2} \mathrm{O}_{5}\right)\right.$ or $\left.\mathrm{AS}_{2}\right)$ via the process of hydroxylation [25]. The physical properties are presented in Table 2 .

$$
\mathrm{Al}_{2} \mathrm{Si}_{2} \mathrm{O}_{5}(\mathrm{OH})_{4} \stackrel{650-800^{\circ} \mathrm{C}}{\longrightarrow} \mathrm{Al}_{2} \mathrm{O}_{3} \cdot 2 \mathrm{SiO}_{2}+2 \mathrm{H}_{2} \mathrm{O}
$$

Metakaolin is classified as an aluminosilicate material that contains varying amounts of alumina (40\%-45\%) and silica $(50 \%-55 \%)$ [25]. It is usually a white powder that consists of particles with a diameter of approximately $2 \mu \mathrm{m}$, which makes it finer than Portland cement (Table 2) [25]. Metakaolin is renowned for its ability to improve the performance of concrete, which can be achieved by reacting with available calcium hydroxide or portlandite to produce secondary calcium silica hydrate $(\mathrm{C}-\mathrm{S}-\mathrm{H})$ and various other hydrates $\left(\mathrm{C}_{4} \mathrm{AH}_{13}, \mathrm{C}_{3} \mathrm{AH}_{6}\right.$, and $\mathrm{C}_{2} \mathrm{ASH}_{8}$ or stratlingite $)$ [26].

Obviously, from available data, it is known that the microstructure and hydrating states impact the chloride resistance properties of concrete. Metakaolin improves the chloride resistance of concrete through the refinement of the pore structure, production of $\mathrm{C}-\mathrm{S}-\mathrm{H}$ from pozzolanic reactions and reduction of chloride attack through the development of Friedel's salt [16]. Friedel's salt (3 $\mathrm{CaO} \cdot \mathrm{Al}_{2} \mathrm{O}_{3} \cdot \mathrm{CaCl}_{2} \cdot 10 \mathrm{H}_{2} \mathrm{O}$ ) is the chemical product from the reaction between chloride ions and $\mathrm{C}_{3} \mathrm{~A}$ [28]. This reduces the effect of permeability in concrete, which makes it more difficult for the chloride ions present in seawater to penetrate the cover concrete and corrode the steel reinforcement.

According to ASTM [29], the summation of the three main oxide constituents, namely, $\mathrm{SiO}_{2}, \mathrm{Al}_{2} \mathrm{O}_{3}$, and $\mathrm{Fe}_{2} \mathrm{O}_{3}$, must be a minimum of $50 \%$ for a material to be categorised as pozzolanic. From Table 3, it can be concluded that all the MK samples used in the various research studies can be classified as pozzolanic.

3.2. Morphology. In scenarios where concrete structures undergo severe loss of compressive strength and durability, for example, in coastal and marine environments, metakaolin proves useful in modifying the fresh and hardened state properties, while also improving the performance of concrete [30]. The performance of MK as supplementary cementitious material is dependent on the particle size distribution and morphological properties of the MK sample. The morphology of MK has a direct impact on the engineering properties of concrete containing MK. Morphology serves as an effective material property for evaluating the viability of $\mathrm{MK}$ as an alternate binder material for combatting chloride attack, with Scanning Electron Microscope (SEM) studies being the most widely utilised technique for defining the morphology of MK.

The SEM investigations conducted by [31-33] revealed that the MK particles are angular and platy in nature 


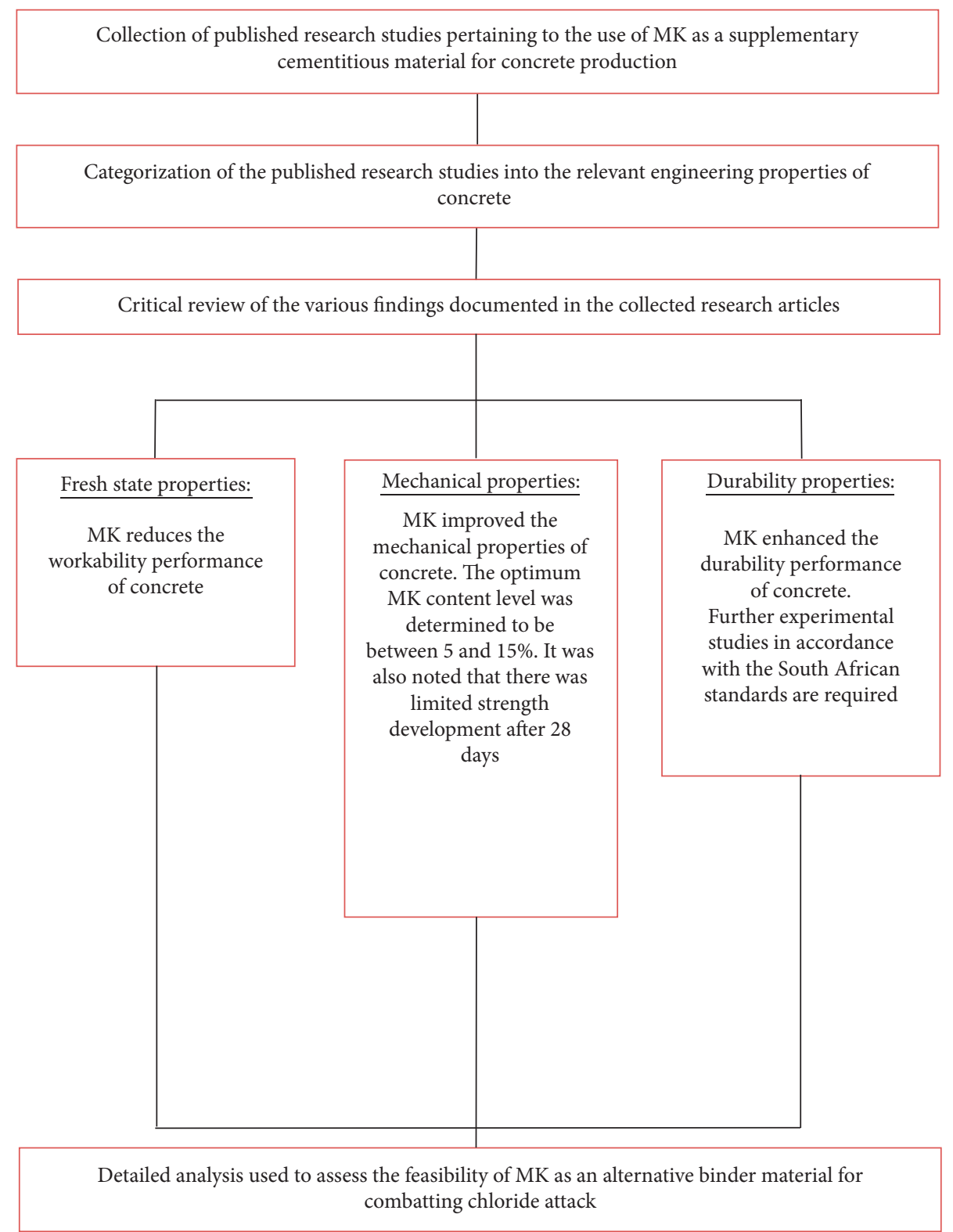

FIGURE 1: Schematic diagram showing the methodology, results, and recommendations.

TABle 2: Physical properties of metakaolin [27].

\begin{tabular}{lc}
\hline Physical property & Description \\
\hline Specific gravity & $2.40-2.60$ \\
Specific surface area & $8-15 \mathrm{~m}^{2} / \mathrm{g}$ \\
Brunauer-Emmett-Teller (BET) surface & $15 \mathrm{~m}^{2} / \mathrm{g}$ \\
area & $80-82 \mathrm{Hunter} \mathrm{L}$ \\
Brightness & Powder \\
Physical form & Off white, gray to \\
Colour & Buff \\
\hline
\end{tabular}

(Figures 2(a) and 2(b)). Yusuf et al. [32] also noted that the surface of the MK particles appeared to be rough. The authors attributed this to the incineration process, followed in manufacturing the MK. The use of metakaolin as an alternative binder system will enhance the compressive strength and durability of concrete. The main factors that contribute to this increase include the filler effect, the dilution effect (physical effect), and the pozzolanic reaction of metakaolin with $\mathrm{Ca}(\mathrm{OH})_{2}$ (chemical effect) forming additional C-S-H gel [34].

Metakaolin used in concrete blends fills the void space between the cement particles to produce a more impermeable concrete structure [35]. The C-S-H gel that is made in the following reaction (see (2) and (3)) is responsible for the strength growth in cement-based concrete [36]:

$$
\begin{aligned}
& \text { Cement }+ \text { Water } \longrightarrow \mathrm{C}-\mathrm{S}-\mathrm{Hgel}+\mathrm{Ca}(\mathrm{OH})_{2} \\
& \mathrm{Ca}(\mathrm{OH})_{2}+\text { Metakaolin } \longrightarrow \mathrm{C}-\mathrm{S}-\mathrm{Hgel}
\end{aligned}
$$

Supplementary cementitious materials can be categorised into two classes: slow reacting and rapid reacting, 
TABLE 3: Chemical composition of MK samples used in past research studies.

\begin{tabular}{|c|c|c|c|c|c|c|c|c|c|c|c|}
\hline \multirow{2}{*}{ Research study } & \multicolumn{11}{|c|}{ Oxides (\%) } \\
\hline & $\mathrm{CaO}$ & $\mathrm{SiO}_{2}$ & $\mathrm{Al}_{2} \mathrm{O}_{3}$ & $\mathrm{Fe}_{2} \mathrm{O}_{3}$ & $\mathrm{MgO}$ & $\mathrm{K}_{2} \mathrm{O}$ & $\mathrm{P}_{2} \mathrm{O}_{5}$ & $\mathrm{SO}_{3}$ & $\mathrm{Na}_{2} \mathrm{O}$ & $\mathrm{TiO}_{2}$ & LOI \\
\hline [16] & 0.03 & 57.37 & 38.63 & 0.77 & 0.07 & 0.49 & 0.61 & 0.15 & 0.39 & 0.40 & 1.04 \\
\hline [18] & 0.09 & 51.6 & 41.3 & 4.64 & 0.16 & 0.62 & - & - & 0.01 & 0.83 & - \\
\hline [19] & 0.78 & 52.68 & 36.34 & 2.14 & 0.16 & 0.62 & - & - & 0.26 & - & 0.98 \\
\hline [20] & 0.05 & 51.2 & 45.3 & 0.6 & - & 0.16 & - & - & 0.21 & - & 0.51 \\
\hline [21] & 0.07 & 52.1 & 41 & 4.32 & 0.19 & 0.63 & - & - & 0.26 & 0.81 & 0.6 \\
\hline [22] & 2.4 & 56 & 37 & 2.4 & 0.3 & 1 & - & - & 1 & 0.2 & - \\
\hline$[23]^{*}$ & - & 51.5 & 44.7 & 0.4 & - & - & - & - & - & 2.1 & - \\
\hline$[23]^{* *}$ & - & 52.5 & 44.5 & 0.9 & - & - & - & - & - & 1.7 & - \\
\hline
\end{tabular}

${ }^{*}$ MK235 (coarser) and ${ }^{* *}$ MK349 (finer).

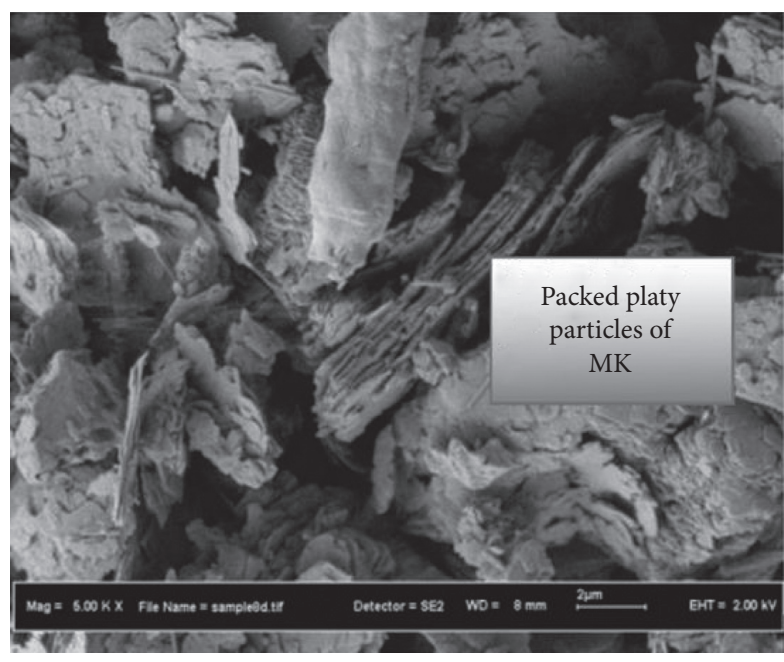

(a)

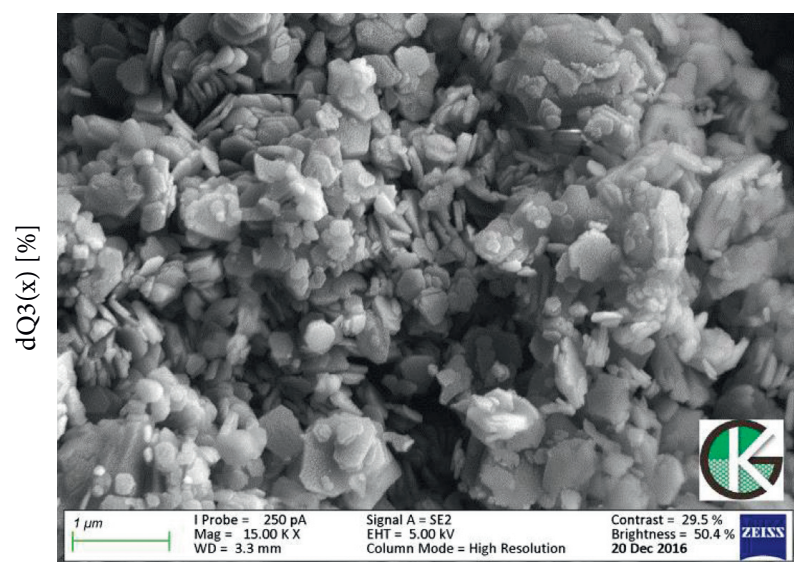

(b)

FIGURE 2: (a) SEM image depicting the shape and roughness of metakaolin particles [32] and (b) SEM particle image of K40 high-reactivity metakaolin [33].

with metakaolin falling into the latter class. Concrete containing metakaolin is expected to have improved short-term performance and superior long-term strengths but not develop any substantial strength after 28 days [26].

3.3. Sustainability and Economic Properties of Metakaolin. Along with improvements to durability performance, metakaolin also enhances the sustainability properties of concrete. This is because the production of metakaolin does not generate chemical $\mathrm{CO}_{2}$ and requires lower temperatures, in comparison with ordinary Portland cement, which involves decarbonating of limestone and requires approximately $1450^{\circ} \mathrm{C}$ [26]. The low energy usage and the reduced $\mathrm{CO}_{2}$ emissions associated with the metakaolin manufacturing process leads to a decrease of roughly $55 \%$ in greenhouse gas emissions.

According to Cassagnabere et al. [37], around $175 \mathrm{~kg}$ of $\mathrm{CO}_{2}$ is emitted for every ton of $\mathrm{MK}$ that is produced, which is significantly lower in comparison with the 1 ton of $\mathrm{CO}_{2}$ that is released for every ton of PC that is manufactured. It has been proved that MK extends the concrete service life, which reduces the need for the concrete to be replaced and subsequently conserves resources.

Figure 3 depicts the projected costs associated with replacing PC with $25 \%$ of FA and 5\% of MK. Despite the fact that the unit costs of $M K(\$ 303 / t$ and $\$ 282 / t)$ are higher than that of PC and FA, the cost evaluation performed by [38] shows that concrete containing MK achieved an overall cheaper mix design. This can be attributed to the inclusion of FA (which is less expensive than PC) as additional cementitious material. Therefore, the research study shows that the more potent material properties of MK outweigh the weaker material properties of FA. At the same time, the cheaper unit cost of FA helps reduce the cost of the mix design, which results in improved strength, durability and economic performance of the concrete [38].

\section{Fresh State Properties of Concrete Containing Metakaolin}

The fresh state lifecycle of concrete typically lasts for a short period and begins once the mixing process has commenced up until the concrete has set [12]. During this time, the 


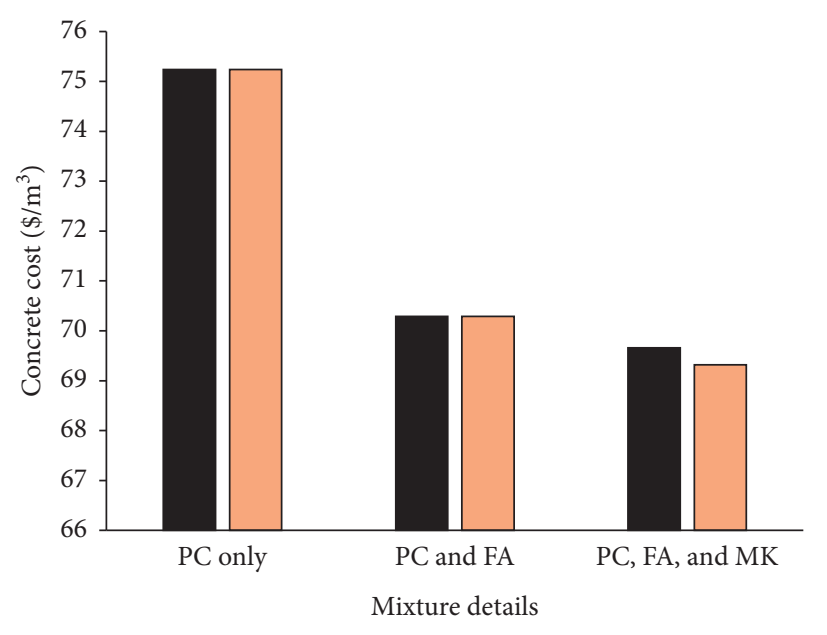

- $\operatorname{MK}(\$ 303 / \mathrm{t})$

$\mathrm{MK}(\$ 282 / \mathrm{t})$

FIGURE 3: Cost summary for producing MK concrete [38].

concrete is usually handled, transported, placed, and vibrated. There is a direct link between the material properties of fresh and hardened concrete, which is visible when observing the reduced workability performance of fresh concrete after the mixing process has concluded. Furthermore, the consistency and degree of vibration applied to the fresh concrete have a direct influence on the strength and durability properties of hardened concrete. Consistency, workability, plastic shrinkage, settlement, and bleeding are considered to be the main fresh state properties for structural concrete [12]. The incorporation of metakaolin as a supplementary cementitious material will impact the fresh state performance of concrete. This section of the review paper will assess the findings acquired from numerous experimental studies into the fresh state properties of concrete containing metakaolin.

4.1. Workability. Owens [12] defines workability as being the ease with which fresh concrete can be placed, vibrated, and finished without any segregation of the constituent materials. Slump is the most commonly used variable for determining the workability performance of concrete in its fresh state. The particle size distribution, particle shape, water-binder $(w / b)$ ratio, temperature, and the amount of admixture added to the concrete mix directly influence the workability properties of concrete [39].

Jagtap et al. [17] investigated the fresh state performance of concrete containing various quantities (i.e., 5, 10, 15, 20, and $25 \%$ ) of $\mathrm{MK}$ as a partial replacement for cement. This was achieved by performing a slump test to quantify the effect MK has on the workability properties of conventional concrete. A $w / b$ ratio of 0.42 was used for all the concrete mix designs. Brooks and Megat Johari [18] further examined the slump performance of concrete mixes containing 5, 10, and $15 \%$ of $\mathrm{MK}$ as a supplementary cementitious material. A constant $w / b$ ratio and superplasticiser content was maintained throughout all concrete mix designs.
As shown in Figure 4, the authors found that the measured slump decreased as the MK content increased. This indicates that the workability of the concrete mix is reduced when the percentage replacement of Portland cement with metakaolin increases. Jagtap et al. [17] attribute this inversely proportional relationship to the reduced fineness modulus of metakaolin, which results in a limited amount of cement paste present to provide the lubricating effect per unit surface area of aggregate.

Brooks and Megat Johari [18] also noted that the incorporation of MK influenced the setting time of the concrete. The authors observed that the initial and final setting times were prolonged until the MK content increased to the $10 \%$ replacement level, while there was a decrease in the setting time after that (Figure 5). This reduction was attributed to the formation of denser binding phases resulting from the increased water demand of MK concrete. As seen in Table 3, the MK sample used by Brooks and Megat Johari [18] contained high concentrations of $\mathrm{SiO}_{2}$ and $\mathrm{Al}_{2} \mathrm{O}_{3}$. This would explain the poor workability properties observed in the test results, as the high oxide percentages will lead to an accelerated hydration process that will subsequently reduce the setting time and decrease the fresh state performance of the concrete.

The abovementioned analysis shows that a minimal amount of experimental research has been undertaken to investigate the fresh state properties of concrete containing MK. However, there was a consistent trend observed in the experimental results obtained by both sets of researchers, which indicates that the addition of MK as a supplementary cementitious material results in reduced concrete workability performance.

\section{Mechanical Properties of Concrete Containing Metakaolin}

The mechanical properties of concrete are quantified by producing, curing, and testing concrete laboratory specimens, with strength (compressive, flexural, and tensile), modulus of elasticity, creep, and shrinkage classified as the main mechanical properties under consideration [40-42]. The concrete strength is an essential variable for the structural design process and is often utilised as a guide when determining the concrete quality and other relevant properties [12]. Structural concrete generally experiences multiaxial stresses that are variable. However, concrete strength is determined from the laboratory testing of small samples that have undergone different handling and curing procedures and have been tested for uniaxial stresses. Therefore, concrete strength that has been determined from laboratory testing only serves as an index of the true strength of concrete structures [12]. The addition of $\mathrm{MK}$ as a partial cement replacement has a significant impact on the mechanical performance of concrete. This section of the review paper will assess the findings acquired from numerous experimental studies into the mechanical properties of concrete containing metakaolin.

5.1. Compressive, Tensile, and Flexural Strengths. The compressive strength of concrete is the most commonly used 


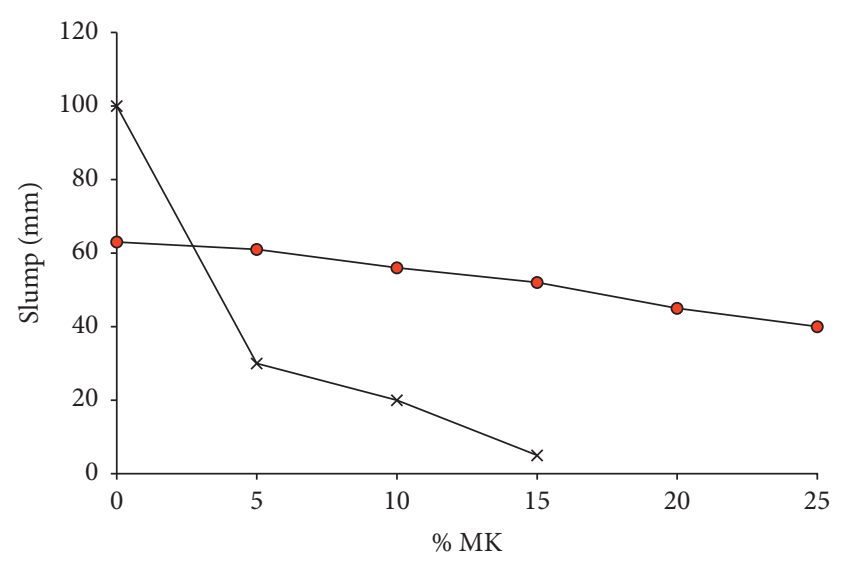

$\multimap-$ Jagtap et al. (2017)

FIGURE 4: Effect of metakaolin on concrete workability [17, 18].

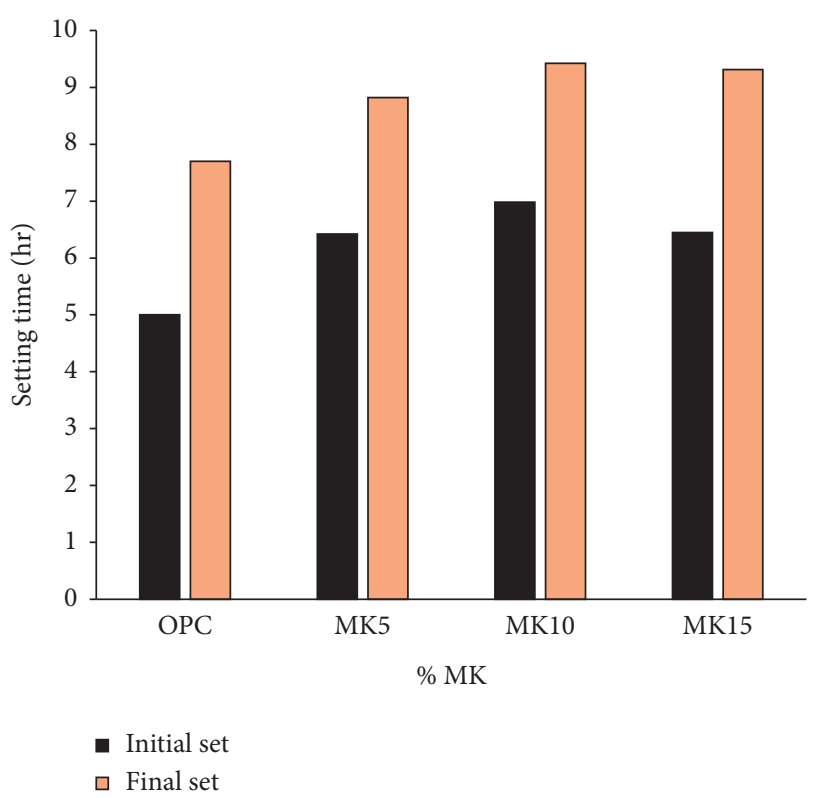

Figure 5: Setting time results for concrete specimens containing metakaolin [18].

parameter for structural engineering and design purposes [12]. Owens [12] goes on to explain that the compressive strength is calculated by dividing the maximum uniaxial load that can be carried by the concrete with the laboratory specimen's cross-sectional area. The cube and core test are the most widely used testing methods for determining the compressive strength of concrete, while the flexural strength test and tensile splitting test are used to calculate the tensile strength $[15,42]$. The flexural strength test consists of exposing concrete beam samples to either two loads located at third points or an individual load placed at midspan [12]. Conversely, the tensile splitting test involves subjecting cylindrical or cube specimens to compressive loads that are applied across two opposed lines [12].

Concrete strength increases with time when sufficient moisture and temperature conditions are provided. In concrete structures, it is found that the compression strength is greater than the flexural strength, which can be attributed to the fact that the $w / b$ ratio, mix properties, aggregate properties, curing conditions, and age affect the compressive and tensile strengths in varying degrees [12].

Güneyisi et al. [19] studied the effect of MK on the mechanical properties of high-performance concretes. This was achieved by conducting compressive strength tests to determine the strength performance of MK concrete. Two control mixtures were designed, with $w / b$ ratios of 0.25 (Control 1) and 0.35 (Control 2). Each control incorporated $5 \%$ and $15 \%$ replacement of cement with metakaolin (by mass). Superplasticisers were also added to the mixtures, to achieve slumps of $100 \pm 20 \mathrm{~mm}$ for samples with a $w / b$ ratio of 0.25 and $150 \pm 20 \mathrm{~mm}$ for samples with a $w / b$ ratio of 0.35 .

The compression strength results attained by Güneyisi et al. [19] in Figure 6 show that the specimens containing metakaolin achieved higher compressive strengths in comparison with the control samples, which is the case for both $w / b$ ratios. This proves that metakaolin improves the bond that occurs between the cementitious material and the aggregate particles, while also increasing the density of the cement paste which ultimately leads to improved compression strength in the concrete [19].

Likewise, Ding and $\mathrm{Li}[20]$ assessed the compressive strength performance of concrete containing varying amounts $(5,10$, and $15 \%)$ of MK as a partial cement replacement. The findings documented indicate that the compressive strength improved as the $\mathrm{MK}$ content increased, with the $15 \% \mathrm{MK}$ specimens achieving the optimum strength results. The authors also noted that there was very limited strength development after 28 days, which is in agreement with similar observations that were made by Wild et al. [21]. This can be attributed to the deceleration of the pozzolanic reaction, which is due to the overall consumption of the calcium hydroxide that is produced during the hydration process.

Sabir et al. [43] conducted a review of the utilisation of metakaolin as a pozzolanic material in concrete. The authors also found that metakaolin provides a major improvement in the development of early strength in concrete, whereas the development of long-term strength is minimal. Kim et al. [22] determined that the optimum MK replacement content was between 10 and $15 \%$ in their experimental study. However, the authors observed that there was no limited strength development after 28 days, which contradicts with the findings from Ding and Li [20] and Wild et al. [21].

Justice et al. [23] evaluated the effect of metakaolins with varying degrees of fineness on the strength properties of concrete. The two types of metakaolin used were MK349 (finer) and MK235 (coarser). Three sample groups were created: an ordinary concrete mix ( $0 \%$ metakaolin), concrete containing $8 \%$ MK235 (by mass), and concrete containing 8\% MK349 (by mass). Superplasticisers were added to the MK235 and MK349 mixes to achieve a slump of 76-102 mm, with the dosage of superplasticiser increasing as the $w / b$ ratio decreased. It was shown that concrete containing metakaolin produced higher strengths and improved durability when compared to the control (Figure 7). The samples containing 


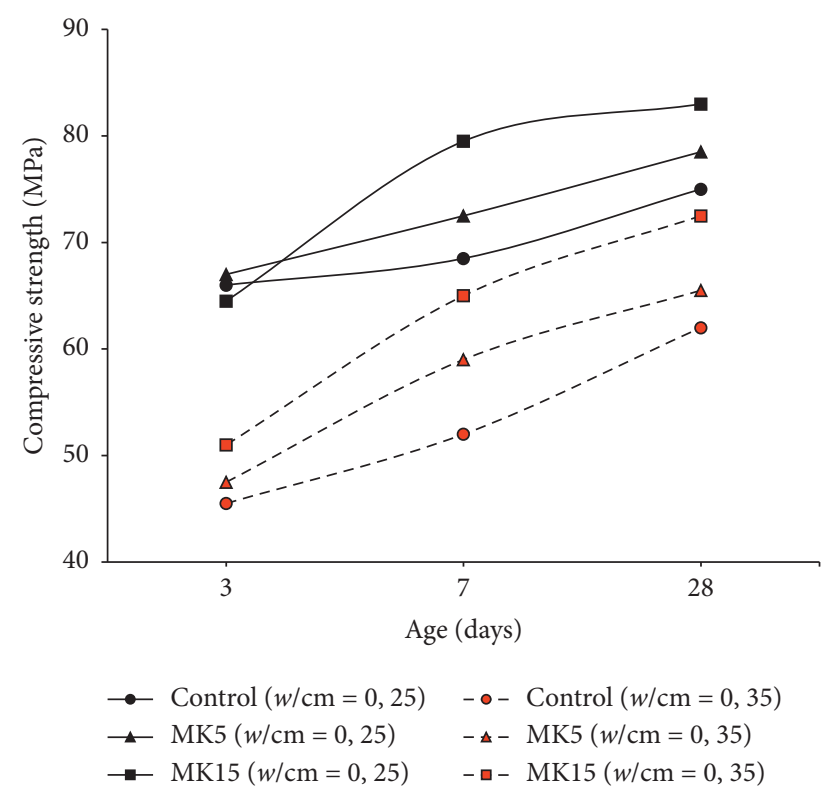

FIGURE 6: Effect of admixtures on compressive strength development in concrete [19].

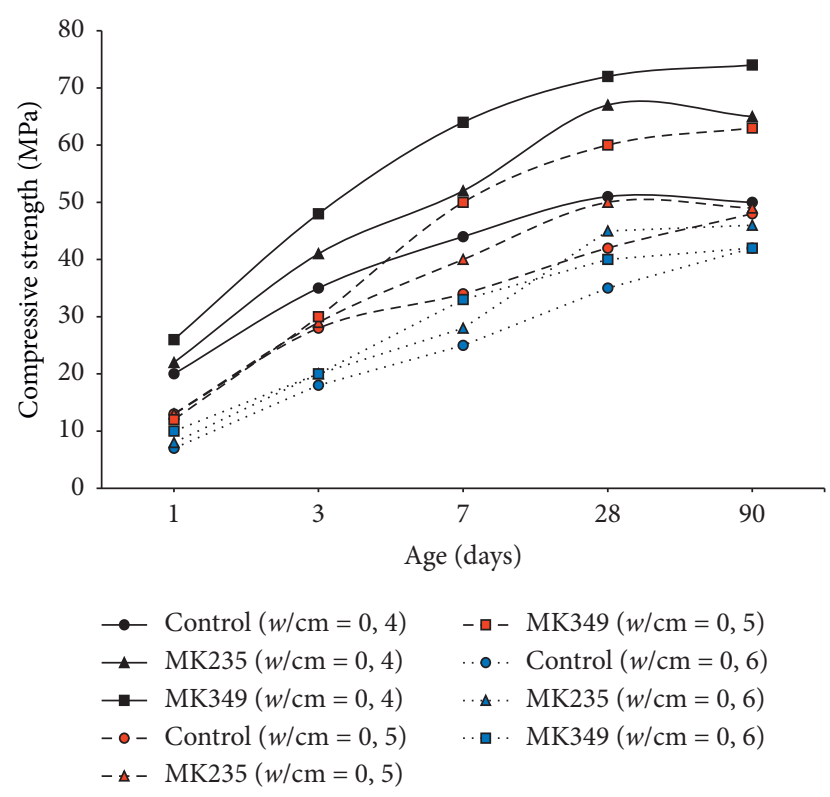

Figure 7: Average compressive strength with respect to concrete age for $w / b=0.40,0.50$, and 0.60 [23].

MK349 (finer) had a more distinct increase in compressive strength. However, the strength increase is not present in the MK349 specimens with a higher $w / b$ ratio, which can be attributed to the sufficient amount of water that was available for the hydration reaction.

From Figure 8, it can be seen that the flexural strength also increased in the concrete beam samples that incorporated metakaolin. It was also noted that the flexural strength decreased as the $w / b$ ratio increased. However, there was no definitive relationship to indicate if MK235 or MK349 is the

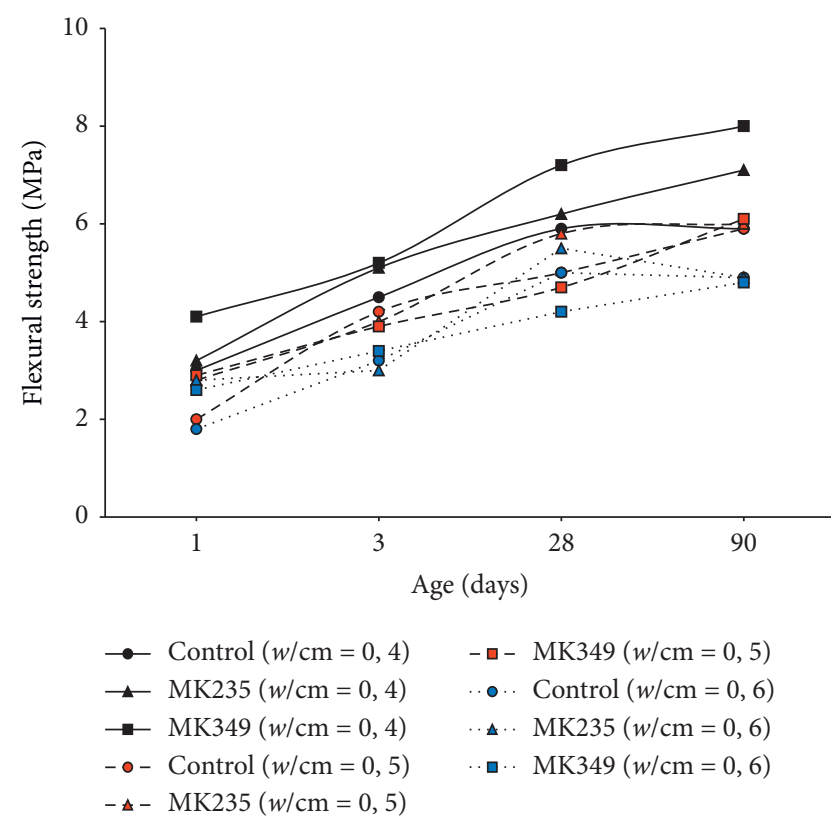

FIGURE 8: Average flexural strength with respect to concrete age for $w / b=0.40,0.50$, and $0.60[23]$.

superior material for improving the flexural strength properties of concrete [23].

Li et al. [16] conducted an experimental investigation to assess the chloride resistance of concrete containing metakaolin and seawater, along with the chloride resistance of concrete exposed to chloride curing conditions. This investigation incorporated $0-6 \%$ replacement of Portland cement with metakaolin. Freshwater (CMK0-6) and artificial seawater (SCMK0-6) were used as the mixing water. Two different curing conditions were implemented: standard curing condition (CMKN0-6 and SCMKN0-6) and chloride curing condition (CMKC0-6 and SCMKC0-6).

Based on the compression test results obtained by $\mathrm{Li}$ et al. [16], it can be seen (Figure 9) that the compressive strength improved with age in all samples except CMKC0 and SCMKC0. The decrease in the 56-day compressive strength in the CMKCO and SCMKCO specimens can be attributed to the chloride attack that is experienced due to exposure to chloride curing conditions. It is also worth noting that the compressive strength results (all MK contents) of the samples cured in a chloride laden setting are significantly higher than that of the control specimens. This indicates the favourable effect metakaolin has on improving the pore structure of concrete, which proves its viability for combatting chloride attack. The results obtained from the compression tests of the CMK and SCMK samples increased along with metakaolin content at both 28 and 56 days. The combination of seawater mixing and curing in $\mathrm{NaCl}$ solution (SCMKC) gives the highest possible compression results [16].

Patil and Jadhav [24] also investigated the effect of chloride attack on M20 grade concrete containing $0 \%, 5 \%$, $10 \%, 15 \%$, and $20 \%$ of metakaolin and silica fume. This was achieved by curing the concrete specimens for 28 days under 


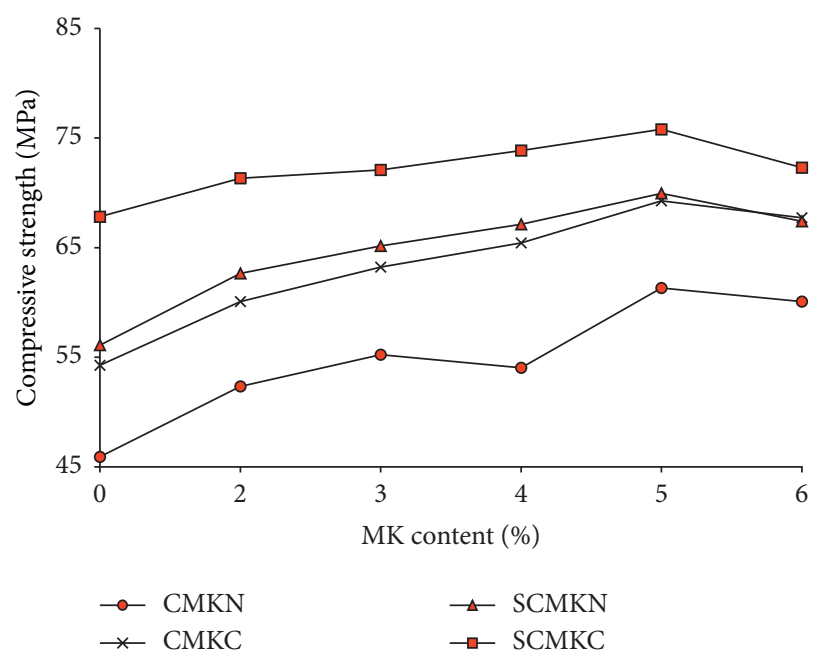

(a)

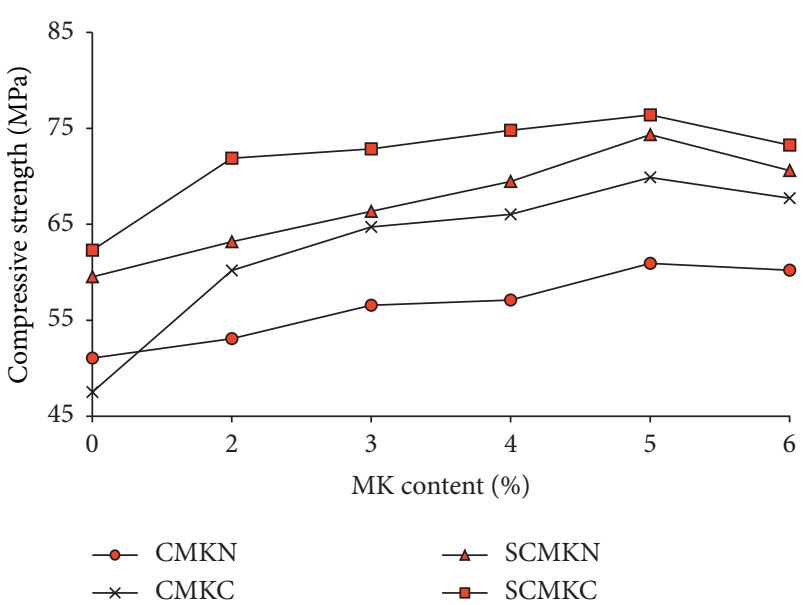

(b)

FIgURE 9: Compressive strength of concrete containing metakaolin at (a) 28 days and (b) 56 days [16].

normal conditions, that is, in a water bath. The samples were then cured in a $5 \% \mathrm{NaCl}$ solution for 60,90 , and 120 days. Similarly, to Li et al. [16], it was determined that the highest compressive strength occurred at $5 \%$ replacement of metakaolin and silica fume (Figure 10). The results acquired indicate that a compressive strength greater than the control samples ( $0 \%$ metakaolin and silica fume) is maintained up until $15 \%$ replacement of metakaolin and silica fume. However, the samples containing 20\% metakaolin and silica fume were found to have compressive strengths lower than the control samples.

From the discussion above, it was observed that experimental studies conducted by Güneyisi et al. [19], Ding and $\mathrm{Li}$ [20], Wild et al. [21], Sabir et al. [43], Kim et al. [22], and Justice et al. [23] showed that MK improved the mechanical properties of concrete, with the $10-15 \%$ replacement level attaining the optimum strength performance. Similarly, Li et al. [16] and Patil and Jadhav [24] investigated the effect of chloride attack on concrete containing MK, with both research studies observing enhanced strength properties in the concrete samples containing MK. However, both studies found the optimum MK content level to be $5 \%$.

The improved strength performance documented in most of the past research studies can be attributed to the favourable effect $\mathrm{MK}$ has on the mechanical properties of concrete. Section 4 of this research paper discussed the influence of $\mathrm{MK}$ on the cement hydration process, which results in the formation of additional C-S-H gel and leads to enhanced strength performance. Table 3 shows that the MK samples used in the experimental investigations contained higher concentrations of $\mathrm{SiO}_{2}$ and $\mathrm{Al}_{2} \mathrm{O}_{3}$ (which are two of the main oxides that make up the chemical composition of pozzolanic materials). The high oxide percentages lead to the formation of extra C-S-H gel, which is responsible for the improved strength properties that were observed. Furthermore, MK also displays similar attributes to a filler material,

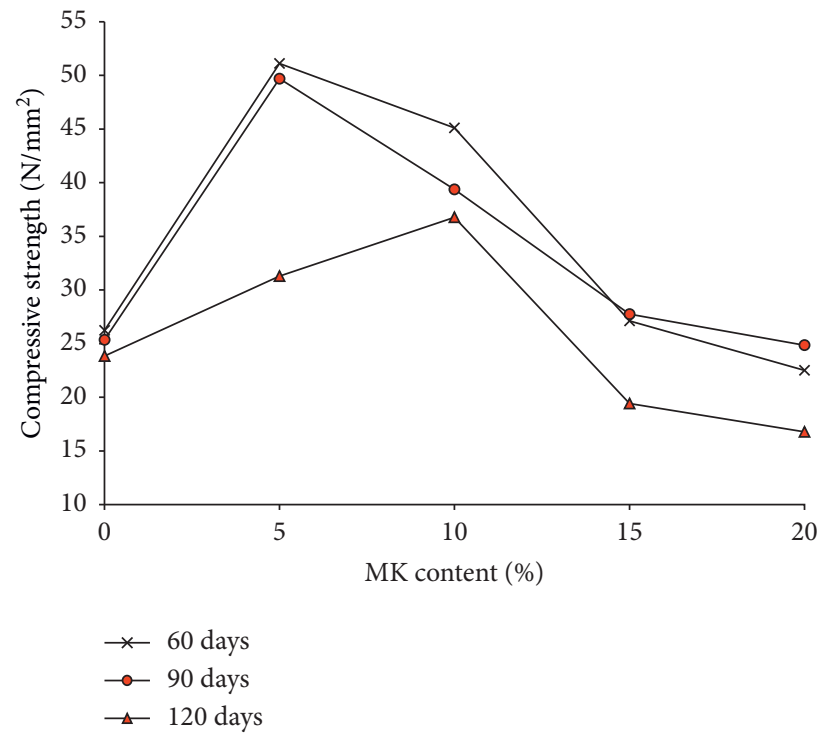

FIgURE 10: Compressive strength for chloride attack [24].

which fills the voids present in the concrete microstructure and therefore reduces the porosity. This improvement to the porosity and microstructure performance will also have a favourable impact on the durability properties of concrete incorporating $\mathrm{MK}$ as an alternate binder material, which will be discussed in Section 6 of this review.

The variation in the optimum MK content level documented across all the research studies can be attributed to various particle sizes and chemical compositions of the numerous MK samples utilised in the experimental investigations. Hence, additional research is needed to quantify the definitive optimum replacement level, particle size distribution, and chemical composition of MK for use as a viable binder material for combatting chloride attack in coastal/marine concrete structures. 


\section{Durability Properties of Concrete Containing Metakaolin}

Durability is defined as being the ability of a concrete structure or component to resist severe exposure conditions for the duration of its design life, without excessive loss of serviceability or need for restoration schemes [12]. The durability of concrete is related to the performance of the concrete, which implies that it may be durable in a particular environment but not in another [12].

The landscape of the concrete construction industry has changed drastically over the last era. There is now an inflated demand for construction projects to be completed in the shortest time possible. This requires the use of high-earlystrength concrete, economical construction materials, minimalistic construction methods, and thin, slender concrete sections with a high steel reinforcement content [12].

Concrete durability is directly linked to the internal pore structure, porosity, and permeation properties of the sample [44]. The durability performance of concrete can be improved by incorporating a supplementary cementitious material that has the overall effect of enhancing the pore structure and enhancing the permeation properties [44].

The transport (permeation, absorption, diffusion, and migration), mechanical, physical, and chemical properties have been provided by Owens [12] as being the most influential on the durability properties of concrete structures. Each property should be correlated with the exposure conditions during the mix design and construction phase. The incorporation of $\mathrm{MK}$ as an alternative binder material has a significant impact on the durability performance of concrete. This section of the review paper will assess the findings acquired from numerous experimental studies into the durability properties of concrete containing metakaolin.

6.1. Resistance to Chloride Attack. Corrosion of steel reinforcement is the most prominent cause of the loss of durability in reinforced concrete structures, with chlorideinduced corrosion being the most prevalent deterioration mechanism in coastal/marine structures $[9,12]$. The exposure conditions and the ability of the cover concrete to protect the reinforcement has a key impact on the frequency with which concrete loses its capacity to resist corrosion.

Concrete delivers excellent physical and chemical protection to steel reinforcement. The hydration of cement produces $\mathrm{Ca}(\mathrm{OH})_{2}$, which is highly alkaline and has a $\mathrm{pH}$ of 12-13 [12]. The alkaline nature of the pore solution provides the perfect conditions to protect the embedded reinforcement from corrosion [45]. Also, it is known that a thin, dense and stable ferric-oxide film, known as the passivating layer, forms on the surface of the steel, which reduces the movement of ions between the concrete and embedded steel [45].

This ultimately leads to a decrease in the corrosion rate. However, with time the corrosion protection in reinforced concrete may be reduced such that the embedded reinforcement begins to corrode. Owens [12] states that the passivating layer can be destroyed by a reduction in the $\mathrm{pH}$ of the concrete and/or by chlorides present at the reinforcement level. If the $\mathrm{pH}$ of the concrete falls below 9 or should the total chloride content exceed a critical value known as the chloride threshold, then the passivating layer and ensuing corrosion protection will be reduced [44].

Along with investigating the mechanical properties of concrete containing metakaolin and seawater (see Section 5.1), Li et al. [16] also assessed the durability performance. The chloride resistance of the concrete specimens was determined using the Rapid Chloride Permeability Test (RCPT). From the results attained in Figure 11, it can be seen that the chloride resistance increased as the metakaolin content and age increased. The addition of metakaolin to the mix and the incorporation of artificial seawater as mixing water provided the most chloride resistance concrete design. This could be accredited to the fact that the addition of metakaolin and seawater improved the concrete microstructure, due to the filling effect, pozzolanic reaction occurring in metakaolin and quickening of hydration by seawater [16].

Microscopy tests were conducted by $\mathrm{Li}$ et al. [16] to determine the effect of chloride attack on the concrete microstructure at $12 \mathrm{~mm}$ and $18 \mathrm{~mm}$ from the surface of the concrete samples. A Scanning Electron Microscope (SEM) was used after 56 days to analyse the pastes that experience chloride curing conditions (PMKC0 and PMKC5) and the pastes that contain seawater (SPMKC0 and SPMKC5).

The microstructure of the control specimen (PMKC0) was found to be porous with coarse corrosion products, which are produced from chloride attack that has taken place at 12 and $18 \mathrm{~mm}$ [16]. It was determined that the microstructure of PMKC5 was porous with fine corrosion products at $12 \mathrm{~mm}$ and denser at $18 \mathrm{~mm}$. However, there were fewer corrosion products in PMKC5, which indicates that the addition of metakaolin reduces the effect of chloride attack in concrete.

In the paste containing seawater and no metakaolin (SPMKC0), the microstructure at $12 \mathrm{~mm}$ was determined to be similar to the microstructure of PMKC5 at $18 \mathrm{~mm}$ [16]. At a working distance of $18 \mathrm{~mm}$, the microstructure was dense and encompassed by deposits of corrosion products. For the SPMKC5 paste, the microstructure at both 12 and $18 \mathrm{~mm}$ was dense with some fine corrosion products present [16]. There were fewer fine corrosion products found at $18 \mathrm{~mm}$, which indicates that seawater mixing and addition of metakaolin improves the chloride resistance of concrete, while also minimising the effect on chloride ingress in the microstructure [16].

In the review conducted by Sabir et al. [43], the authors also reported that metakaolin adjusted the pore structure of concrete, to improve its resistance to transportation and diffusion of chloride ions, which is the leading cause of chloride attack in concrete structures. The results from the RCPT conducted by Justice et al. [23] indicate that metakaolin reduced the permeability of the concrete in comparison with the high permeability readings that were generated for the control specimens (Figure 12). The samples containing MK235 (coarser) are the most effective in decreasing the amount of charge passing through the concrete, 


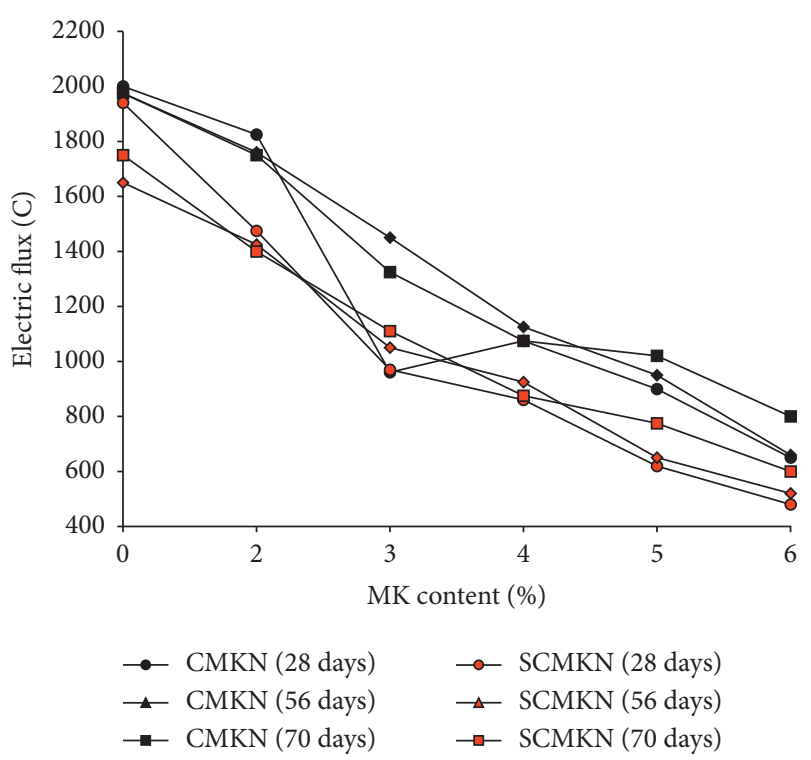

FIGURE 11: Total charge passing through concrete under RCPT [16].

whereas the results obtained for the MK349 (finer) samples ranged from very low to moderate (Figure 12) [23].

6.2. Water Absorption and Porosity. Water absorption via submersion is an important parameter for analysing the durability performance of concrete. It defines the porosity properties by quantifying the percentage of water that is absorbed into the concrete microstructure when the laboratory specimen is immersed and is linked to the square root of time $[13,39]$. Results obtained from the water sorptivity test (Figure 13) conducted by Güneyisi et al. [19] indicate that metakaolin improves the permeability properties of concrete. Güneyisi et al. [19] also found that the sorptivity coefficient decreased as the $w / b$ ratio was reduced. An inversely proportional relationship exists between the sorptivity coefficient and mechanical properties, which implies that the specimens producing the highest compressive strength have the lowest sorptivity coefficients. Low sorptivity coefficients indicate a finer pore structure, which is a vital criterion for reducing the effect of chloride ingress in coastal/marine environments. This is attributed to the pore refinement resulting from filling and the secondary hydration reaction that occurs in mineral admixtures [19].

Based on the analysis of past experimental investigations that were performed in this section of the review paper, it can be seen that extensive research has been undertaken to determine the effect MK has on the durability performance of concrete. The common trend present across all past year studies shows that MK has a favourable effect on the durability properties of concrete. This can be attributed to the filler effect, whereby the MK particles (which are significantly smaller than PC particles) fill the voids present in the concrete microstructure and thus produce more impermeable concrete. This improvement to the porosity and microstructure properties also proves that incorporating

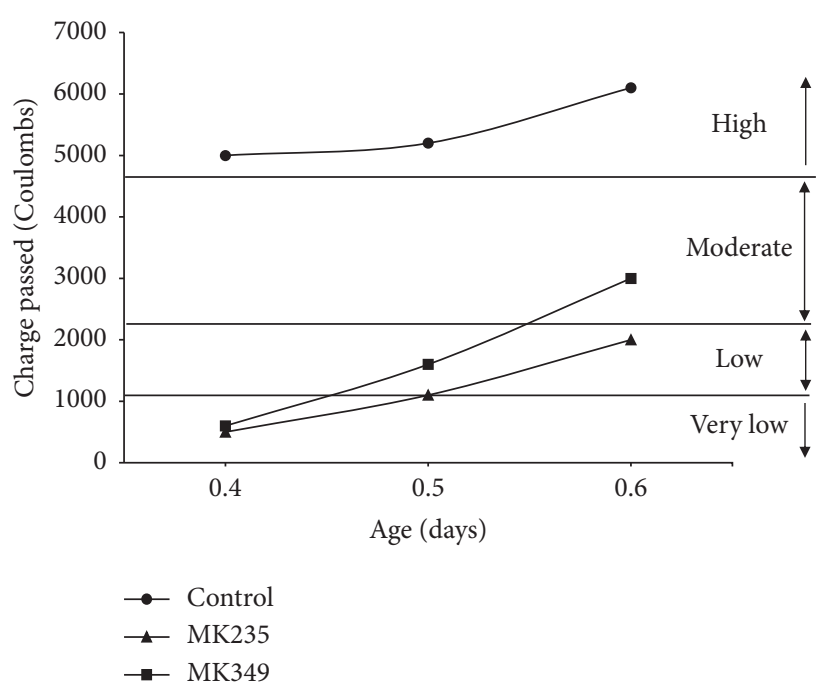

Figure 12: Results from the rapid chloride permeability test (RCPT) after 28 days [23].

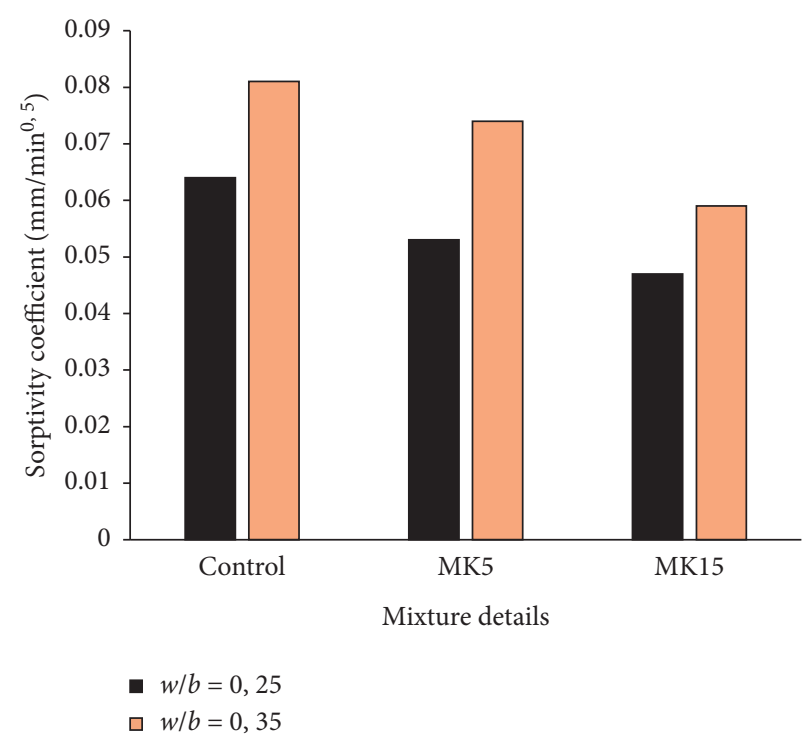

FIGURE 13: Effect of admixtures on the sorptivity coefficient of concrete [19].

MK as supplementary cementitious material is a suitable strategy for combatting chloride attack in coastal/marine concrete. However, it was also noted that the durability properties of MK concrete had not been assessed in accordance with the South African durability standards for concrete. Therefore, additional experimental research is needed to evaluate the durability performance of concrete containing MK in the South African context.

\section{Concluding Remarks}

This review paper included a critical analysis of the performance characteristics of concrete containing $\mathrm{MK}$ as a partial cement replacement. The concrete properties assessed in this study include: fresh state and mechanical and 
durability properties. The main findings documented across the numerous research studies that have been reviewed in this paper are summarised in Table 1. The following conclusions were noted in the presented review:

(i) Workability (slump and setting time) decreased as the MK replacement level increased.

(ii) Mechanical properties (compressive and flexural strength) improved as the MK content increased. The optimum MK replacement content was determined to fall between 5 and $15 \%$, with a notable reduction in the concrete strength properties beyond this replacement level.

(iii) Durability performance improved with the incorporation of $\mathrm{MK}$.

The low concrete workability observed in the MK concrete mixes can be attributed to the variations in the particle size distribution of MK and PC. The MK particles are significantly finer than PC particles, which means that MK has a high-water demand for the hydration process to take place. As documented in the past year studies, the increased water demand for concrete containing $\mathrm{MK}$ is also responsible for accelerating the setting time after the $10 \%$ MK replacement level.

The enhanced strength properties documented in the past research studies can be associated with the pozzolanic reaction that occurs between the $\mathrm{MK}$ and $\mathrm{Ca}(\mathrm{OH})_{2}$, which leads to the formation of additional C-S-H gel. In addition, MK also exhibits similar characteristics as a filler material, which enables the much finer MK particles to fill the voids present between the PC particles. This results in MK concrete displaying reduced porosity, which indicates improved microstructure properties and highlights the advantageous impact MK has on the durability performance of concrete. The favourable development of strength and durability observed in concrete containing MK coupled with the lack of chemical $\mathrm{CO}_{2}$ emitted during the $\mathrm{MK}$ manufacturing process shows the valuable impact MK can have on enhancing the sustainability and serviceability performance of concrete. This also proves the feasibility of $\mathrm{MK}$ as an alternate binder material for combatting chloride attack in coastal/marine concrete structures.

As discussed previously, there was a common agreement across all past year studies, which proved that MK reduces the workability performance of concrete. However, there was a variation in the $w / b$ ratios adopted in the experimental investigations. Therefore, further research is needed to assess the role a higher $w / b$ ratio could play in improving the workability performance of concrete containing MK. There was also a notable disparity in the optimum MK content level documented across all the past research studies. Hence, future experimental investigations are required to determine the definitive optimum content level, particle size distribution, and chemical composition of MK for use as a feasible supplementary cementitious material. Although extensive research was undertaken to analyse the durability performance of $\mathrm{MK}$ concrete, the authors also noted that the relevant durability testing procedures were not conducted in accordance with the South African durability index tests. Therefore, further experimental research is required to determine the durability performance of concrete containing $\mathrm{MK}$ as an alternate binder material in the South African setting.

\section{Data Availability}

The datasets generated during the current study are available from the corresponding author on request.

\section{Conflicts of Interest}

The authors declare that they have no conflicts of interest.

\section{References}

[1] J. Broomfield, Corrosion of Steel in Concrete, Taylor \& Francis, London, UK, 2007.

[2] K. Tamanna, S. N. Raman, M. Jamil, and R. Hamid, "Utilization of wood waste ash in construction technology: a review," Construction and Building Materials, vol. 237, p. $117654,2020$.

[3] M. Schneider, "The cement industry on the way to a lowcarbon future," Cement and Concrete Research, vol. 124, p. 105792, 2019.

[4] G. C. H. Doudart de la Grée, Q. L. Yu, and H. J. H. Brouwers, "Upgrading and evaluation of waste paper sludge ash in ecolightweight cement composites," Journal of Materials in Civil Engineering, vol. 30, no. 3, Article ID 04018021, 2018.

[5] N. B. Singh and B. Middendorf, "Geopolymers as an alternative to Portland cement: an overview," Construction and Building Materials, vol. 237, p. 117455, 2020.

[6] M. G. Alexander, Marine Concrete Structures: Design, Durability and Performance, Elsevier Science, Amsterdam, The Netherlands, 2016.

[7] M. U. Khan, S. Ahmad, and H. J. Al-Gahtani, "Chlorideinduced corrosion of steel in concrete: an overview on chloride diffusion and prediction of corrosion initiation time," International Journal of Corrosion, vol. 2017, Article ID 5819202, 9 pages, 2017.

[8] M. H. Tadayon, M. Shekarchi, and M. Tadayon, "Long-term field study of chloride ingress in concretes containing pozzolans exposed to severe marine tidal zone," Construction and Building Materials, vol. 123, pp. 611-616, 2016.

[9] P. Awoyera, A. Adesina, O. B. Olalusi, and A. Viloria, "Reinforced concrete deterioration caused by contaminated construction water: An overview," Engineering Failure Analysis, vol. 116, Article ID 104715, 2020.

[10] W. Chalee, C. Jaturapitakkul, and P. Chindaprasirt, "Predicting the chloride penetration of fly ash concrete in seawater," Marine Structures, vol. 22, no. 3, pp. 341-353, 2009.

[11] A. M. Aguirre-Guerrero and R. M. de Gutiérrez, "Assessment of corrosion protection methods for reinforced concrete," in Ecofficient Repair and Rehabilitation of Concrete Infrastructures, Elsevier, Cambridge, UK, pp. 315-353, 2018.

[12] G. Owens, Fundamentals of Concrete, The Concrete Institute, Midrand, South Africa, 3rd edition, 2013.

[13] K. R. Kumar, G. Shyamala, P. O. Awoyera, K. Vedhasakthi, and O. B. Olalusi, "Cleaner production of self-compacting concrete with selected industrial rejects-an overview," Silicon, pp. 1-12, 2020. 
[14] T. Ayub, N. Shafiq, and S. Khan, "Durability of concrete with different mineral admixtures: a review," International Journal of Civil and Environmental Engineering, vol. 7, no. 8, 2013.

[15] D. L. Pillay, O. B. Olalusi, and M. M. Mostafa, "A review of the engineering properties of concrete with paper mill waste ash-towards sustainable rigid pavement construction," Silicon, pp. 1-17, 2020.

[16] Q. Li, H. Geng, Y. Huang, and Z. Shui, "Chloride resistance of concrete with metakaolin addition and seawater mixing: a comparative study," Construction and Building Materials, vol. 101, pp. 184-192, 2015.

[17] S. A. Jagtap, M. N. Shirsath, and S. L. Karpe, "Effect of metakaolin on the properties of concrete," International Research Journal of Engineering and Technology, vol. 4, no. 7, pp. 643-645, 2017.

[18] J. J. Brooks and M. A. Megat Johari, "Effect of metakaolin on creep and shrinkage of concrete," Cement and Concrete Composites, vol. 23, no. 6, pp. 495-502, 2001.

[19] E. Güneyisi, M. Gesoğlu, S. Karaoğlu, and K. Mermerdaş, "Strength, permeability and shrinkage cracking of silica fume and metakaolin concretes," Construction and Building Materials, vol. 34, pp. 120-130, 2012.

[20] J. T. Ding and Z. Li, "Effects of metakaolin and silica fume on properties of concrete," Materials Journal, vol. 99, no. 4, pp. 393-398, 2002.

[21] S. Wild, J. M. Khatib, and A. Jones, "Relative strength, pozzolanic activity and cement hydration in superplasticised metakaolin concrete," Cement and Concrete Research, vol. 26, no. 10 , pp. $1537-1544,1996$.

[22] H.-S. Kim, S.-H. Lee, and H.-Y. Moon, "Strength properties and durability aspects of high strength concrete using Korean metakaolin," Construction and Building Materials, vol. 21, no. 6, pp. 1229-1237, 2007.

[23] J. M. Justice, L. H. Kennison, B. J. Mohr et al., "Comparison of two metakaolins and a silica fume used as supplementary cementitious materials," in Proceedings of the Seventh International Symposium on Utilisation of High-Strength/High Performance Concrete, vol. 228, Washington D.C., USA, June 2005.

[24] R. P. Patil and H. S. Jadhav, "Comparative study of effect of temperature and chloride on silica fume concrete and metakaolin concrete," International Journal of Scientific \& Engineering Research, vol. 5, no. 3, 2014.

[25] J. M. Khatib, Sustainability of Construction Materials, Woodhead Publishing, Cambridge,UK, 2nd edition, 2016.

[26] M. Zeljkovic, Metakaolin Effects on Concrete Durability, Masters. University of Toronto, Toronto, Canada, 2009.

[27] S. N. Patil, A. K. Gupta, and S. S. Deshpande, "MetakaolinPozzolanic material for cement in high strength concrete," in Proceedings of the 2nd International Conference on Emerging Trends in Engineering (SICETE'13), pp. 46-49, Maharashtra, India, March 2013.

[28] M. Maes, E. Gruyaert, and N. De Belie, "Resistance of concrete against combined attack of chlorides and sulphates," International Congress on Durability of Concrete, vol. 53, 2012.

[29] ASTM, Standard Specification for Coal Fly Ash and Raw or Calcined Natural Pozzolan for Use in Concrete, ASTM, West Conshohocken, PA, USA, 2008.

[30] G. Murali and P. Sruthee, "Experimental study of concrete with metakaolin as partial replacement of cement," International Journal Emerging Trends in Engineering and Development, vol. 4, no. 2, pp. 344-348, 2012.

[31] J. D. Bapat, Mineral Admixtures in Cement and Concrete, CRC Press, Boca Raton, FL, USA, 2012.
[32] T. O. Yusuf, M. Ismail, J. Usman, and A. H. Noruzman, "Impact of blending on strength distribution of ambient cured metakaolin and palm oil fuel ash based geopolymer mortar," Advances in Civil Engineering, vol. 24, Article ID 658067, 2014.

[33] Kaolin Group, Data Sheet - Metakaolin KG-K40, Kaolin Group, Gurugram, Haryana, 2018.

[34] H. M. Khater, "Influence of metakaolin on resistivity of cement mortar to magnesium chloride solution," CeramicsSilikáty, vol. 54, no. 4, pp. 325-333, 2010.

[35] M. Narmatha and D. T. Felixkala, "Meta kaolin -the best material for replacement of cement in concrete," IOSR Journal of Mechanical and Civil Engineering, vol. 13, no. 4, pp. 66-71, 2016.

[36] S. Aiswarya, G. Prince Arulraj, and C. Dilip, "A review of use of metakaolin in concrete," Engineering Science and Technology: An International Journal, vol. 3, no. 3, 2013.

[37] F. Cassagnabere, M. Lachemi, G. Escadeillas et al., "Flash Metakaolin/slag/cement binder: an environmental and performantial alternative for steam-cured mortar for precast use," in Proceedings of the Annual Conference of the Transportation Association of Canada, pp. 1-10, Vancouver, Canada, September 2010.

[38] NLK Consultants Inc, Ecosmart Concrete Project Metakaolin Pre-feasibility Study, NLK Consultants Inc, BC V6B 2W2, Canada, 2002.

[39] A. Babafemi, B. Šavija, S. Paul, and V. Anggraini, "Engineering properties of concrete with waste recycled plastic: a review," Sustainability, vol. 10, no. 11, p. 3875, 2018.

[40] T. Ayub, S. U. Khan, and F. A. Memon, "Mechanical characteristics of hardened concrete with different mineral admixtures: a review," The Scientific World Journal, vol. 2014, pp. 1-15, Article ID 875082, 2014.

[41] M. S. Kirgiz, "Strength gain mechanisms of blended-cements containing marble powder and brick powder," KSCE Journal of Civil Engineering, vol. 19, no. 1, pp. 165-172, 2015.

[42] M. S. Kirgiz, "Strength gain mechanism for green mortar substituted marble powder and brick powder for Portland cement," European Journal of Environmental and Civil Engineering, vol. 20, no. sup1, pp. s38-s63, 2016.

[43] B. B. Sabir, S. Wild, and J. Bai, "Metakaolin and calcined clays as pozzolans for concrete: a review," Cement and Concrete Composites, vol. 23, no. 6, pp. 441-454, 2001.

[44] A. Saleh, Chloride Induced Corrosion and Sulphate Attack - A Literature Review on Concrete Durability, NTNU, Trondheim, Norway, 2008.

[45] C. G. Berrocal, K. Lundgren, and I. Löfgren, "Corrosion of steel bars embedded in fibre reinforced concrete under chloride attack: state of the art," Cement and Concrete Research, vol. 80, pp. 69-85, 2016. 